\title{
Insight of the Iron Binding and Transport in Dke1 - A Molecular Dynamics Study
}

\author{
Hrvoje Brkić
}

Faculty of Medicine, J. Huttlera 4, HR-31000 Osijek, Croatia

Author's e-mail address: hbrkic@mefos.hr

RECEIVED: June 18, 2015 * REVISED: November 20, 2015 * ACCEPTED: November 25, 2015

Abstract: Acetylacetone dioxygenase from Acinetobacter johnsonii (Dke1) is a non-heme $\mathrm{Fe}^{2+}$ dependent enzyme which catalyzes the oxidative degradation of $\beta$-dicarbonyl compounds. It is a homotetramer with four active sites, each containing single metal ion. Since the active site is buried, knowledge on transport of the metal ion and reactants (products) is essential for understanding the enzyme mechanism. The goal of this study was to assess the influence of several point mutations on the enzyme activity. The point mutations of hydrophilic amino acid residues (Tyr70, Arg80 and Glu98) that were shown to be important for metal binding and reactants stabilization were of the particular interest. Computational study enabled us to determine the preferred metal ion binding sites as well, as the pathways it utilizes to enter the enzyme active site. Besides, influence of the point mutations on the hydrogen bond network within enzyme was determined.

Keywords: metaloenzyme, non-heme, iron, molecular dynamics.

\section{INTRODUCTION}

A PPROXIMATELY one quarter to one third of all proteins require metals to carry out their functions. ${ }^{[1]}$ One of such proteins is the Acetylacetone dioxygenase from Acinetobacter johnsoii (Dke1), which belongs to the family of $\mathrm{Fe}^{2+}$ dependent dioxygenases. It is a homotetramer ${ }^{[2]}$ with each subunit organized in a single-domain $\beta$-barrel fold, characteristic for the cupin superfamily of proteins. Dke1 catalyzes the oxidative degradation of the $\beta$-dicarbonyl compounds ${ }^{[3,4]}$ and for this purpose it needs $\mathrm{Fe}^{2+}$ ion. In the crystallographically determined structure the metal ion is coordinated with three histidines, while the molecular dynamics study showed that beside the histidines one glutamate could also take part in the metal ion coordination. ${ }^{[5]}$ Although the Dke1 active site, besides the $\mathrm{Fe}^{2+}$ ion, can host several other metal ions, such as $\mathrm{Co}(\mathrm{II})$, $\mathrm{Ni}(\mathrm{II}), \mathrm{Cu}(\mathrm{II})$ and $\mathrm{Zn}(\mathrm{II})$, the enzyme is unable to catalyze the oxidative conversion of acetylacetone in their presence. ${ }^{[4]}$ Until now only the effects of hydrophilic residues, placed in the second coordination sphere of the metal, have been investigated computationally, using the mole- cular dynamics (MD) simulations. ${ }^{[5]}$ The main purpose of this study was to get insights into molecular mechanisms of Dke1, which haven't been demystified by now. Using computational methods the specific and non-specific metal ion binding sites are revealed and amino acid residues responsible for metal transport in and out of the Dke1 active site are identified. Additionally, the influence of hydrophilic residues mutations on the metal ion affinity and stabilization of ligand, i.e. 2,4-pentandione (PD), is investigated. Since the experimental data had suggested that hydrophilic residues in the active site pocket, Tyr70, Arg80 and Glu98, play a crucial role in the metal ion and substrate stabilization, ${ }^{[6]}$ the point mutations of these amino acids were computationally prepared, and their influence to the protein structure and dynamics as well as on ligands binding and transport were investigated by computational methods. Previously published data reported that Dke1 has 2 metal binding sites, ${ }^{[7]}$ but until now only one of them has been specified. In this study the alternative metal ion binding site(s) was determined and mechanism of the metal ion circulation within the protein was elucidated. 


\section{METHODS}

\section{System Preparation}

The crystal structure of the substrate free Dke1 obtained from the PDB database ${ }^{[8]}$ (pdb_id 3BAL) was used as the initial structure for the simulations. Several systems were prepared, as follows.

The point mutants Glu98GIn, Arg80Ala and Tyr70Ala, were prepared by editing the PDB file and using the module tleap (part of the AMBER12 package). ${ }^{[9]}$ Water molecules determined in the crystal structure were removed, and zinc was replaced with the $\mathrm{Fe}^{2+}$ ion. Systems were parameterized using the AMBER ${ }^{[9]} \mathrm{ff} \mathrm{O}^{[10]}$ force field, GAFF ${ }^{[11]}$ (General Amber force field), and the parameters for $\mathrm{Fe}^{2+}$ ion that were derived and tested earlier. ${ }^{[5,12]}$ Parameters development was achieved with ab initio quantum mechanical calculations (using UHF method). ${ }^{[5]}$ Equilibrium values for the bond distances, angles, and dihedrals, were determined, as well as their corresponding force constants. According to the experimental conditions, ${ }^{[2-5]}$ the all simulations were performed at $\mathrm{pH} 7.5$. Histidines were uncharged (singly protonated), aspartic and glutamic acids were negatively, and arginines and lysines positively charged. All other amino acid residues were neutral except the $\mathrm{N}$ and $\mathrm{C}$ terminal residues which were positively and negatively charged, respectively. Hydrogen atoms were also added by tleap, while protonation of the histidine imidazole ring (either $\mathrm{N} \delta 1$ or $\mathrm{N} \varepsilon 2$ ) was adjusted manually depending on the possibilities of hydrogen bond formation. The complexes with PD (2,4 pentandione) were constructed using the earlier determined Dke1-PD complex ${ }^{[5]}$ as a template. For the complexes, besides the already mentioned force fields, the parameters derived earlier for the $\mathrm{Fe}^{2+}$ - substrate (PD) interactions were used. ${ }^{[5]}$

\section{Simulations}

Systems were placed in the truncated octahedron box filled with TIP3P ${ }^{[13]}$ water molecules, with minimal distance of 9 Á between the solute atoms and the edge of the box. Neutralization was accomplished by adding $\mathrm{Na}^{+}$ions at the appropriate places on the protein surface.

Minimization of the systems was done in four, and equilibration in seven cycles, for details see previously conducted studies. ${ }^{[5,12]}$ After minimization and equilibration each of the constructed mutants, (Arg80Ala, Glu98GIn and Tyr70Ala) as well as their complexes with PD, were submitted to $30 \mathrm{~ns}$ of unconstrained MD simulation. The time step during pre-equilibration, equilibration and the first 2 ns of the productive MD simulations was $1 \mathrm{fs}$, and remaining simulations were accomplished using the SHAKE algorithm ${ }^{[14]}$ and 2 fs time step.
Besides the simulations where $\mathrm{Fe}^{2+}$ was described with both bonding and non-bonding parameters, several sets of MD simulations with the metal ion placed at different positions and described with non-bonding parameters solely were also performed. For the wild type and mutated proteins several sets of $\mathrm{MD}$ simulations were performed: a) with the $\mathrm{Fe}^{2+}$ ion initially placed into the active site (crystallographically determined pose), two sets of simulations, $16 \mathrm{~ns}$ and $30 \mathrm{~ns}$ each, b) with $\mathrm{Fe}^{2+}$ placed at the entrance of the water trafficking tunnels, 3 sets of simulations for the wild type enzyme (WT; 16, 6 and 3 ns long), 2 sets for the Tyr70Ala (16 and 5 ns) mutant and one for each the other two variants (16 ns)). Starting structures for these simulations were the final snapshots of the $5 \mathrm{~ns}$ long simulations with $\mathrm{Fe}^{2+}$ placed at (or close to) the entrance of the water trafficking tunnels, where one water molecule was replaced a with $\mathrm{Fe}^{2+}$. Table ST1 (in Supplemental) contains list of all the preformed simulations with its respective duration.

\section{The Binding Free Energy Calculations for $\mathrm{Fe}^{2+}$ Initially Placed in a Water Tunnel}

The free energy for the hydrated $\mathrm{Fe}^{2+}$ binding to the enzyme was calculated using the MMPBSA ${ }^{[15]}$ method as implemented in the AMBER package. Calculations were done on the 2-ns long final parts of the MD simulation trajectories. The concentration of the singly charged counterions was 0.1 M. Poisson-Boltzmann method was used to calculate the polar component of solvation, and non-polar component was determined using equation (1):

$$
\Delta_{\text {sol }} H_{\text {nonpolar }}=\gamma \mathrm{SASA}
$$

where $\gamma$ is the surface tension with value of $0.0072 \mathrm{kcal} \mathrm{mol}^{-1}$ $\AA^{-2}$. Solvent accessible surface area (SASA) was calculated using the MolSurf program. ${ }^{[16]}$ The calculations were accomplished for the enzyme immersed into the solvent utilizing the solute dielectric constant of 4.0. As a ligand $\mathrm{Fe}^{2+}$ ion hydrated with two water molecules (the $\mathrm{Fe}^{2+}+$ two water molecules cluster) was considered, while the receptor was apo variant.

\section{RAMD Simulations}

Random acceleration molecular dynamics (RAMD ${ }^{[17]}$ simulations were used in order to determine the metal ion exiting paths and roughly estimate relative expulsion speed for the metal bound to different Dke1 variants. For each system (WT, Glu98Gln, Arg80Ala and Tyr70Ala) 4 runs were performed in each chain, altogether 54 runs. Simulations were done for 250 ps or until the distance between the protein and the $\mathrm{Fe}^{2+}$ centres of mass became greater than $30 \AA$. The time step was $1 \mathrm{fs}$, and the acceleration amplitude was $0.23 \mathrm{kcal} / \mathrm{mol} / \AA \AA \mathrm{g} / \mathrm{g}$. The direction of the force was kept for 40 time steps $(40 \mathrm{fs})$. If a ligand did not move by more 
Table 1. Percentage of the simulation time during which the hydrogen bonds between Glu98(OE1/2)-His104(NE2) and Glu11(OE1/2)-His104(NE2) exists, Simulations were performed on APO variants of Dke1

\begin{tabular}{ccccc}
\hline & WT & Tyr70Ala & Arg80Ala & Glu98GIn \\
\hline Glu11(OE1/2)-His104(NE2) & 0.07 & 0 & 7.6 & 0.2 \\
Glu98(OE1/2)-His104(NE2) & 56.3 & 73.8 & 19.1 & 5.4 \\
\hline
\end{tabular}

than $0.01 \AA$ A during this period, a new direction was chosen randomly; otherwise the same force was applied for the next period of 40 time steps.

The structures were sampled every $1.0 \mathrm{ps}$ and trajectories were analysed in details. Root mean square deviation, amino-acid fluctuations, water population of the enzyme active site, hydrogen bonds between amino acids of interest and other interesting features were monitored and analysed using the program ptraj ${ }^{[18]}$ available within the Amber program suite.

\section{Secondary Structure Analysis}

The secondary structure of the simulated variants was determined by STRIDE WEB server. ${ }^{[19]}$

\section{RESULTS AND DISCUSSION}

In order to get insights into the molecular mechanisms of $\mathrm{Fe}^{2+}$ trafficking in and out of the enzyme active site, a set of MD simulations for the wild type protein and its single point mutants Tyr70Ala, Arg80Ala Glu98GIn and were performed: (i) of the $\mathrm{Fe}^{2+}$ free protein (apo enzyme), (ii) of the enzyme with $\mathrm{Fe}^{2+}$ bound in the active site, without and with applying random force, (iii) of the proteins with the metal ion located at the entrance of the water tunnel. The obtained trajectories were analysed and the $\mathrm{Fe}^{2+}$ migration paths, in and out of the protein, were determined.

\section{(i) Simulations on APO Enzymes}

A short, only 6 ns long, MD simulations of Dke1 wild type and its variants Tyr70Ala, Arg80Ala Glu98GIn and in their metal free form were performed in order to monitor influence of the point mutations on the overall protein structure and particularly on the active site structure. According to the calculated RMSD between the structure of the wild type enzyme and the mutants (1.7 Tyr70Ala, 2.4 Arg80Ala, 1.9 Glu98GIn) and the visual inspection it is clear that the mutations neither change the overall protein fold nor the secondary structure elements, $B$ sheets they are part of. However, due to differences in size, hydropobicity and other physico-chemical properties of the amino acid residues in the native enzyme and mutants their local environment, as well as protein flexibility, have changed. A comparison of the resulting trajectories revealed that Glu98 was more than $50 \%$ of the simulation time H-bonded to His104 in the WT and Tyr70Ala mutant, while in the other two mutants this interaction is significantly weaker and it has disappeared during simulation, and both Glu98 and His104 were more flexible (see Table 1). Another carboxylate residue that was found rather close to the metal binding motif, Glu11 (from neighbour subunit), was generally not $\mathrm{H}$-bonded to any of the metal binding histidines or hydrophilic triad residues (Tyr70Ala, Arg80Ala, Glu98GIn) and pointed away from the active site in all variants (see Table 1 ). A Figure 1 shows the optimized structure of the active site in different variants obtained after 6 ns of MD simulations.

\section{(ii) MD Simulations with the $\mathrm{Fe}^{2+}$ Ion Bound into the Protein Active Site Defined by 3 His}

During MD simulations with the $\mathrm{Fe}^{2+}$ cofactor bound to the metal binding motif, which is according to the crystallographically determined Dke1 structure characterized with 3 histidines, Glu98 entered the metal ion coordination sphere

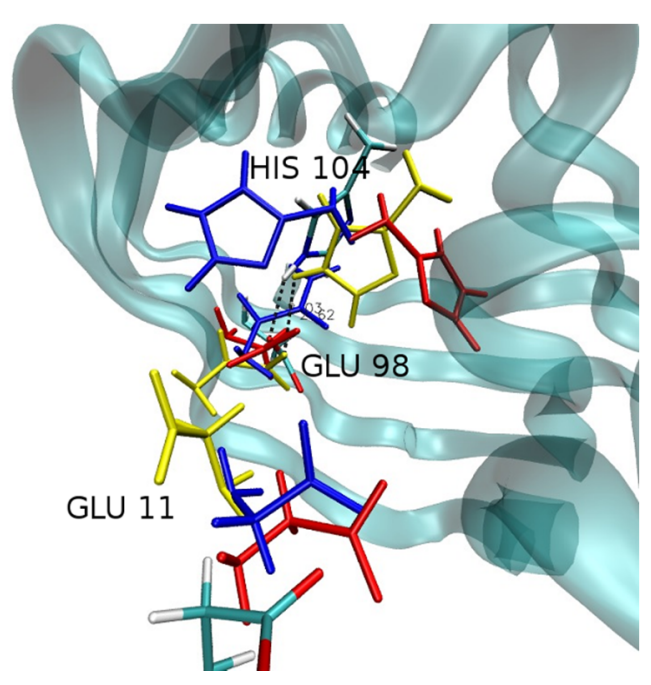

Figure 1. Glu11 (from neighbouur subunit) and Glu98 orientation; - in WT and in the Tyr70Ala mutant Glu98 is bound to the His104, while in other mutants it is free to move. His104, Glu98 and Glu11 are shown in stick representation with each variant coloured differently: WT by atom names, Tyr70Ala yellow, Arg80Ala red and Glu98GIn blue. Optimized structures obtained after 6 ns of MD simulations are shown. Figure is created using VMD. [20] 
Table 2. Interactions between the metal ion and Glu/GIn98 during the simulations with the iron ion described with both bonding and non-bonding parameters. First two rows show the percentage of the time for Glu/GIn98-Fe ${ }^{2+}$ type of interaction. In last two rows distance $(\AA)$ between the iron and the carboxyl Glu/Gln side chain oxygens is given

\begin{tabular}{ccccc}
\hline & WT & Tyr70Ala & Arg80Ala & Glu98Gln \\
\hline Monodentate coordination & 73.5 & 65.2 & 32.6 & 45.4 \\
Bidentate coordination & 16.7 & 8.4 & 33.3 & - \\
Average distance of closer oxygen & 2.5 & 2.6 & 2.5 & 3.1 \\
Average distance of farther oxygen & 3.7 & 4.5 & 3.1 & - \\
\hline
\end{tabular}

Table 3. Hydrogen bond analyses, percentage of the each bond persistent time is given. "Cplx" extension denotes complex with $P D$, "free" denotes ligand free protein with a metal ion in the active site and " ${ }^{\prime \prime}$ denotes systems with Fe ${ }^{2+}$ initially placed into one of the water tunnels. X-not found; One letter notation for aminoacids is used to reduce space in table *data already published by Brkić et al. [5]

\begin{tabular}{|c|c|c|c|c|c|c|c|c|c|c|c|c|c|}
\hline & & $\begin{array}{c}\text { E98Q } \\
\text { cplx }\end{array}$ & $\begin{array}{l}\text { E98Q } \\
\text { free }\end{array}$ & E98QT & $\begin{array}{l}\text { Y70A } \\
\text { cplx }\end{array}$ & $\begin{array}{l}\text { Y70A } \\
\text { free }\end{array}$ & Y70AT & $\begin{array}{l}\text { R80A } \\
\text { cplx }\end{array}$ & $\begin{array}{l}\text { R80A } \\
\text { free }\end{array}$ & R80AT & $\begin{array}{l}\text { WT* }^{*} \\
\text { cplx }\end{array}$ & $\begin{array}{l}\text { WT* } \\
\text { free }\end{array}$ & WTT \\
\hline GLY68 (O) & GLU98 (N) & 99.9 & 99.5 & 9.9 & 74.6 & 75.0 & $x$ & 99.5 & 99.9 & 99.9 & 74.0 & 100 & $x$ \\
\hline GLY68 (O) & GLU98 (C) & 63.5 & $x$ & 13.9 & 2.9 & 13.0 & $x$ & $x$ & $x$ & $x$ & $x$ & 5.0 & $x$ \\
\hline GLU11 (OE12) & HIE104 (NE2) & 43.5 & $x$ & 4.9 & 24.4 & $x$ & $x$ & $x$ & 100.0 & 23.5 & 3.0 & 84.0 & 11.1 \\
\hline ARG80 (NE) & GLU98 (OE1/2) & $x$ & $x$ & 6.4 & 36.9 & 15.3 & 69.9 & $x$ & $x$ & $x$ & 34.0 & 63.0 & 21.3 \\
\hline ARG80 (NH2) & GLU98 (OE1/2) & $x$ & $x$ & 25.0 & 58.8 & 92.5 & 81.0 & $x$ & $x$ & $x$ & 20.0 & 64.0 & 61.4 \\
\hline GLU98 HB(2,3) & GLU11 (OE1/2) & 100.0 & $x$ & 63.8 & $x$ & $x$ & $x$ & $x$ & $x$ & 17.4 & 3.6 & 7.2 & $x$ \\
\hline GLU98 (OE12) & HIE104 (NE2) & 14.2 & 61.5 & 10.2 & 27.2 & $x$ & 36.0 & 68.8 & $x$ & 2.6 & 49.4 & $x$ & 27.9 \\
\hline
\end{tabular}

and most of the simulated time coordinated the metal ion either monodentately or bidentately in all variants (see Table 2). A typical orientation of Glu98 during the simulations is shown in Figure 2a. Most of the time during which Glu98 monodentately coordinated $\mathrm{Fe}^{2+}$ its other carboxyl oxygen was H-bonded to Arg80, in both the WT protein $^{[5]}$ and in the Tyr70Ala mutant (64 \% and $92.5 \%$ of the time, respectively).
Intriguingly, increased bidentate coordination of metal ion lead to reorientation of Glu11, and formation of the stable $\mathrm{H}$-bond between Glu11 and His104 in the resting WT protein and the Arg80Ala mutant (during $84 \%$ and $100 \%$ of the simulation time, respectively, see Table 2 and Table 3). Glu11 changed its orientation and, showed a notable propensity of $\mathrm{H}$-bonding to $\mathrm{His} 104$ in variants Glu98GIn and Tyr70Ala (Table 3). Differently, in the ligand

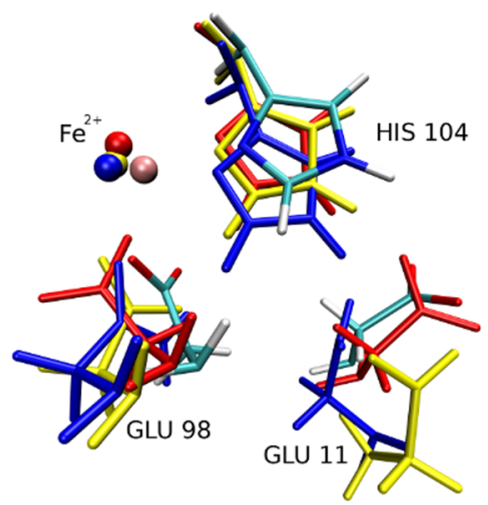

A

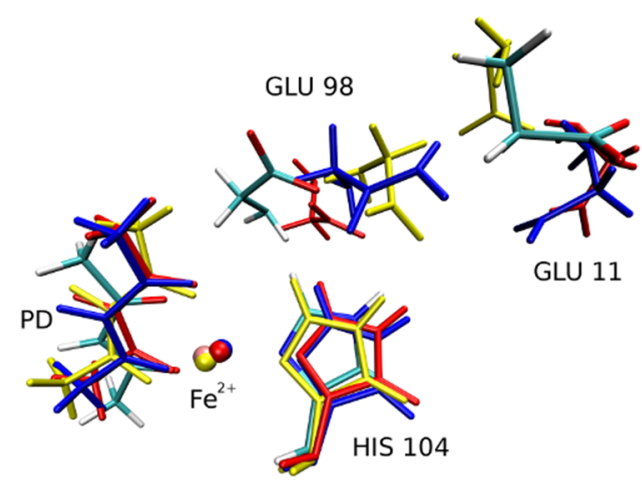

B

Figure 2. Orientation of residues Glu98, Glu11 (from neighbor subunit) and His104 in the different variants with the metal ion in the enzyme active site a) without substrate bound and b) with substrate bound. Stick representation colored by atoms represents WT system, red is Arg80Ala mutant, yellow is Tyr70Ala mutant and blue is Glu98GIn mutant. 
Table 4. Persistence (\% of the simulation time is given) of hydrogen bonds between residues Arg80 - His104, and Met117 - His 64 in simulations of Dke1-PD complexes. The iron ion was described with both bonding and nonbonding parameters

\begin{tabular}{ccccc}
\hline & WT & Tyr70Ala & Arg80Ala & Glu98Gln \\
\hline Arg80(NH2) - His104(Ne2) & - & 20 & - & 27 \\
Met117(Ce) - His64(Nd1) & 54 & 13 & 32 & 14 \\
\hline
\end{tabular}

free protein this $\mathrm{H}$-bond was mostly present in the WT protein and the Arg80Ala mutant. Further on it was noticed that in the complexes Tyr70Ala-PD and Glu98GIn-PD the residue Arg80 is $\mathrm{H}$-bonded to His104 during about 20-30\% of the simulation time (see Table 4). Interactions between Glu11, His104 and Glu98 in the simulated complexes are shown in Figure $2 b$.

\section{(iii) Simulations of the Systems with Substrate Bound to Dke1}

The substrate, PD, binding to the active site induced expulsion of the Glu98 from the $\mathrm{Fe}^{2+}$ coordination sphere in all variants. During the simulations PD coordinated the metal ion bidentately, while Glu98 reoriented preserving its interactions with Arg80 in the WT protein (either with Ne, $34 \%$, or with $\mathrm{NH} 2,20 \%$ of the simulation time) and in the Tyr70Ala mutant (with Ne, $37 \%$, and with NH2 $59 \%$ of the simulation time). In the variants Glu98GIn and Arg80Ala interactions between Arg80 and Glu98 were not established during the simulations. Arg80 NH2 interacted with $\mathrm{C} \delta$ of His104 during $28 \%$ and $26 \%$ of the simulation time in the Glu98GIn and Tyr70Ala mutants, respectively, while in other systems there was no such interaction. The interaction between Glu98 and His104 was the strongest in the Arg80Ala variant, follows WT, see Table 3.

To summarize, in the substrate bound complexes, the coordinate bond between Glu98/Gln98 and $\mathrm{Fe}^{2+}$ ion was lost in all variants, leading to a $3-\mathrm{His}$ and diketonate ligated Fe(II) center. Instead, Glu98 interacted with His104 while intensity of this interaction varied among Dke1 variants (see text above and Table 3). Glu11 changed its orientation and, showed a notable propensity of $\mathrm{H}$-bonding to His104 in variants Glu98GIn and Tyr70Ala (Table 3). Differently, in the ligand free protein this $\mathrm{H}$-bond was mostly present in the WT protein and the Arg80Ala mutant. Further on it was noticed that in the complexes Tyr70Ala-PD and Glu98GIn-PD the residue Arg80 is H-bonded to His104 during about $20-30 \%$ of the simulation time (see Table 4). Interactions between Glu11, His104 and Glu98 in the simulated complexes are shown in Figure $2 b$.

\section{(iv) $\mathrm{Fe}^{2+}$ Detachment from the Active Site}

In order to trace the putative trajectories of $\mathrm{Fe}^{2+}$ when migrating out of the active site set of MD simulations was performed in which the metal ion was described by nonbonding parameters only. The simulations were performed a) without and b) with an additional random force applied to the metal ion (details of the simulations are given in Materials and Methods).

\section{(iv a) $\mathrm{Fe}^{2+}$ Migration out of the Metal Binding Site - no Additional Force}

During MD simulations at room temperature with $\mathrm{Fe}^{2+}$ described only with its charge $\left(1.5 \mathrm{e}^{+}\right)$and the van der Waals parameters migration of the metal ion out of the active site in all variants was noticed. At the end of the first $5 \mathrm{~ns}$ of $\mathrm{MD}$ simulations, about $2 / 3$ of the metal binding sites were already empty in the Arg80Ala and the Glu98GIn variants, see Table 5.

The analysis of trajectories sampled for the WT protein and the Tyr70Ala mutant revealed that during $46 \mathrm{~ns}$ of $\mathrm{MD}$ simulations $\mathrm{Fe}^{2+}$ spent, on average, $30-35 \%$ of the simulation time in the active site (data averaged over all subunits). However, resistance of the metal ion to leave His62, His64 and His104 was significantly lower in the Arg80 and Glu98 variants (see Table 5). Such behaviour of metal ion is consistent with the binding free energies (precisely, the binding enthalpies) calculated using MM_PBSA method (see Table 6).

The metal ion migration can be traced in Figure 15 (see supplementary material) where its distance from the initial (3His, Glu) position is given. While in the Arg80Ala mutant $\mathrm{Fe}^{2+}$ ions left the metal binding site very fast, in the WT protein they migrated from and back to the active sites and rarely moved more than $3.5 \AA$ Á away from their initial positions (Figure 1S, supplementary material).

In order to understand/rationalize mechanism of $\mathrm{Fe}^{2+}$ detachment from the active site metal coordination and the His104-Glu98-Arg80 interactions (see Figures $2 \mathrm{~S}$ and $3 \mathrm{~S}$ in supplementary material) were analysed. During the simulations Glu98 (in the case of the Glu98GIn variant,

Table 5. Percentage (\%) of simulation time (averaged over all subunits) during which $\mathrm{Fe}^{2+}$ was present in the active site, i.e. coordinated with tree histidines and Glu98

\begin{tabular}{ccccc}
\hline $\begin{array}{c}\text { Simulation } \\
\text { time (ns) }\end{array}$ & WT & Arg80Ala & Glu98Gln & Tyr70Ala \\
\hline first 5 & 69.1 & 36.9 & 32.0 & 55.1 \\
46 & 34.8 & 9.1 & 16.9 & 28.3 \\
\hline
\end{tabular}


Table 6. Relative energies $(\mathrm{kcal} / \mathrm{mol})$ for the binding of the hydrated $\mathrm{Fe}^{2+}$ (cluster of two water molecules and metal ion) to different Dke1 variants. Energy was calculated for each chain (A - D) using MM_PBSA approach. Energy for the metal binding to the $C$ subunit of the WT enzyme was used as a referent

\begin{tabular}{cccccc}
\hline Variant & A & B & C & D & Average \\
\hline WT & 24.4 & 6.7 & 0.0 & 32.0 & 15.8 \\
Tyr70Ala & 19.4 & 46.9 & 42.4 & 35.4 & 36.0 \\
Arg80Ala & 44.5 & 21.0 & 27.4 & 32.5 & 31.0 \\
Glu98Gln & 60.2 & 43.6 & 45.3 & 45.0 & \\
\hline
\end{tabular}

Gln98) coordinates the metal ion either monodentately or bidentately. Ratio of bi/mono coordination is highest in the Arg80Ala mutant, follows the Tyr70Ala one (see Table 7). During simulations of the WT protein Glu98 was coordinating the metal ion in the active site $\left(\mathrm{Fe}^{2+}\right.$ bound to three histidines) monodentately most of the time. At the same time the other carboxyl oxygen of the Glu98 was interacting via $\mathrm{H}$-bond with Arg80. The metal migration out of the active site was accompanied with the Arg80-Glu98 separation. Due to reorientation of Arg80 (moving away from the metal centre), the $\mathrm{H}$-bond between Arg80 and Glu98 broke resulting with increased mobility of Glu98. Subsequently Glu98 moved away from the metal binding site, and pulled the $\mathrm{Fe}^{2+}$ ion with itself (green and purple line in Figure 3S in supplementary material (WT) graphs). After that Glu11 reoriented, and took part in the metal ion coordination. The transient coordination of the metal ion by Glu11 and Glu98 was proposed to be important for $\mathrm{Fe}^{2+}$ transport in and out of the protein (see Figure 3). Since in the case of the Arg80Ala there is no Arg80 to constrain Glu98 motions it almost instantaneously (see Table 8), i.e. at the very beginning of MD simulation, pulled the metal ion out of the 3 His binding site. Glu98 remained either bidentantely coordinated to the $\mathrm{Fe}^{2+}$ or it established hydrogen bond with His104 (see Figure $3 \mathrm{~S}$ in supplementary material).

In the Glu98GIn variant no H-bond between $\mathrm{Gln} 98$ and either His104 or Arg80 was present during the simulation while the $\mathrm{Fe}^{2+}$ ion was in the active site. However, when the $\mathrm{Fe}^{2+}$ left the active site $\mathrm{Gln} 98$ hydrogen bonded to His104 (see Figures $1 S$ and $2 S$ i.e. subunit $D$ in supplementary material).

Table 7. Percentage of simulation time during which Glu/GIn98 coordinatesFe ${ }^{2+}$ monodentately/bidentately. The iron ion was described by nonbonding parameters only

\begin{tabular}{ccccc}
\hline Coordination & WT & Tyr70Ala & Arg80Ala & Glu98Gln \\
\hline Monodentate & 97.5 & 87.5 & 77.3 & 70.8 \\
Bidentate & 2.5 & 4.8 & 22.7 & 0 \\
ratio[bi/mono] & 0.02 & 0.06 & 0.3 & 0 \\
\hline
\end{tabular}

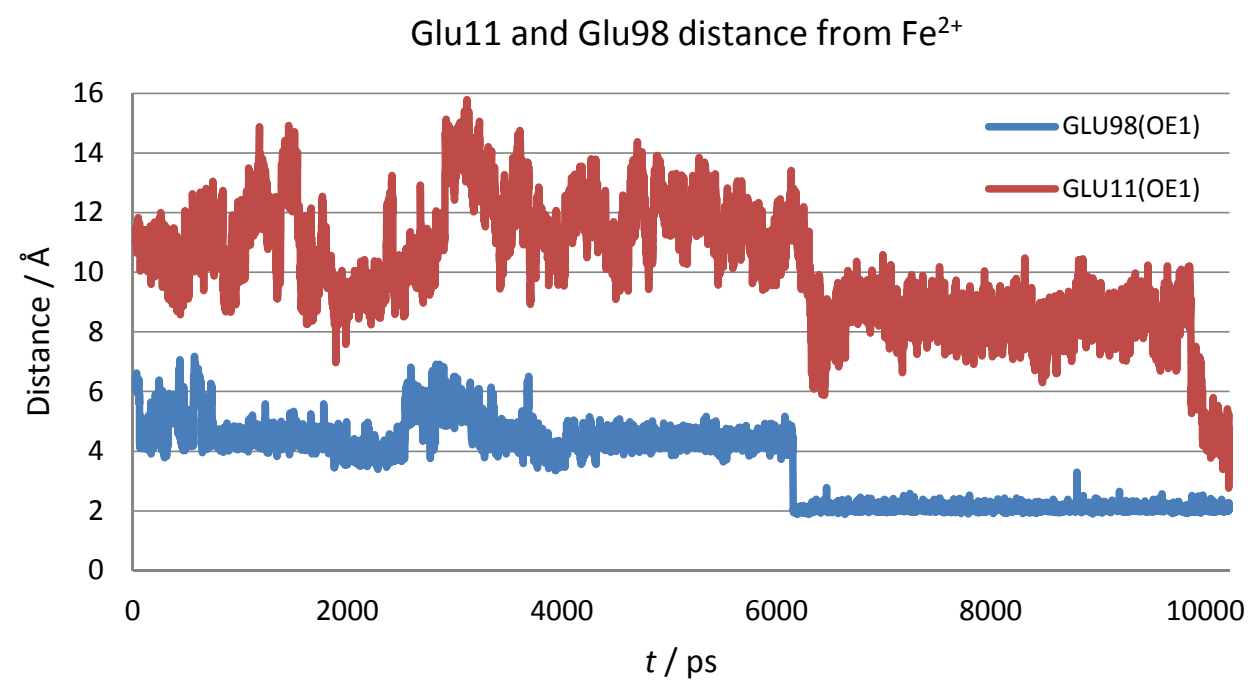

Figure 3. The Glu98(OE1) - $\mathrm{Fe}^{2+}$ and Glu11(OE1) - $\mathrm{Fe}^{2+}$ distances during $10 \mathrm{~ns}$ of MD simulations (the iron ion was described by nonbonding parameters only). The figure supports assumption that both Glu residues, Glu11 and Gu98, are important in the metal ion transportation, into and out of, the active site. 
Table 8. $\mathrm{Fe}^{2+}$ positions (and their 'population') at the end of RAMD simulations. For each variant 16 RAMD simulations were performed. In the cases when the metal ion was expelled from the protein the number of expulsions through tunnel T2 (entrance defined by Glu11, see Figure 4) is given in square brackets

\begin{tabular}{|c|c|c|c|c|}
\hline $\mathrm{Fe}^{2+}$ location & WT & Tyr70Ala & Arg80Ala & Glu98GIn \\
\hline Out of protein [near Glu11] & $2[2]$ & $4[3]$ & $5 *$ & $3[2]$ \\
\hline Glu11 neighbor sub. & 3 & 8 & 4 & 6 \\
\hline Phe119 and Glu98 & 0 & 3 & 3 & 6 \\
\hline Thr107 and Glu78 & 7 & 0 & 0 & 0 \\
\hline Random & 4 & 1 & 4 & 1 \\
\hline
\end{tabular}

* in this mutants the water tunnels T1 and T2 cannot be distinguished (i.e. the Arg80 which is border between their entrances does not exist), however Glu11 still plays important role in of the metal ion expulsion

\section{(iv b) The Detachment of $\mathrm{Fe}^{2+}$ from the Active Site by Applying Random Force}

In another approach $\mathrm{Fe}^{2+}$ expulsion from the active site enhanced by the random force was simulated. In the presence of random force the metal ion detachment from the active site appeared in the much shorter time scale than noticed during 'regular MD' simulations (previous paragraph). Instead of one, a several simulations for the same 'computer cost' could be performed, result of which was the statistical distribution of the $\mathrm{Fe}^{2+}$ detachment pathways. The fate of the $\mathrm{Fe}^{2+}$ over a time range of $250 \mathrm{ps}$ was monitored, and the end positions of the ions are summarized in Table 8.
In most cases the metal ion expelled from the $3 \mathrm{His}$ metal binding site ended close to Glu11 in all enzyme variants. In short, results showed that the mechanism of primary $\mathrm{Fe}^{2+}$ detachment out of the enzyme active site found by RAMD simulations is comparable to that described in the previous section. In the starting structure the $\mathrm{Fe}^{2+}$ was coordinated with 3 histidines and Glu98 (Figure 4S(A) in supplementary material), during the simulations the $\mathrm{Fe}^{2+}$ ion was pulled out of the active site by Glu98 but its coordination with His104 was still preserved (Figure 4S(B)). In the third step Glu98 moved $\mathrm{Fe}^{2+}$ away from His104 (Figure $4 \mathrm{~S}(\mathrm{C}))$ in the direction of Glu11 from the neighbor subunit
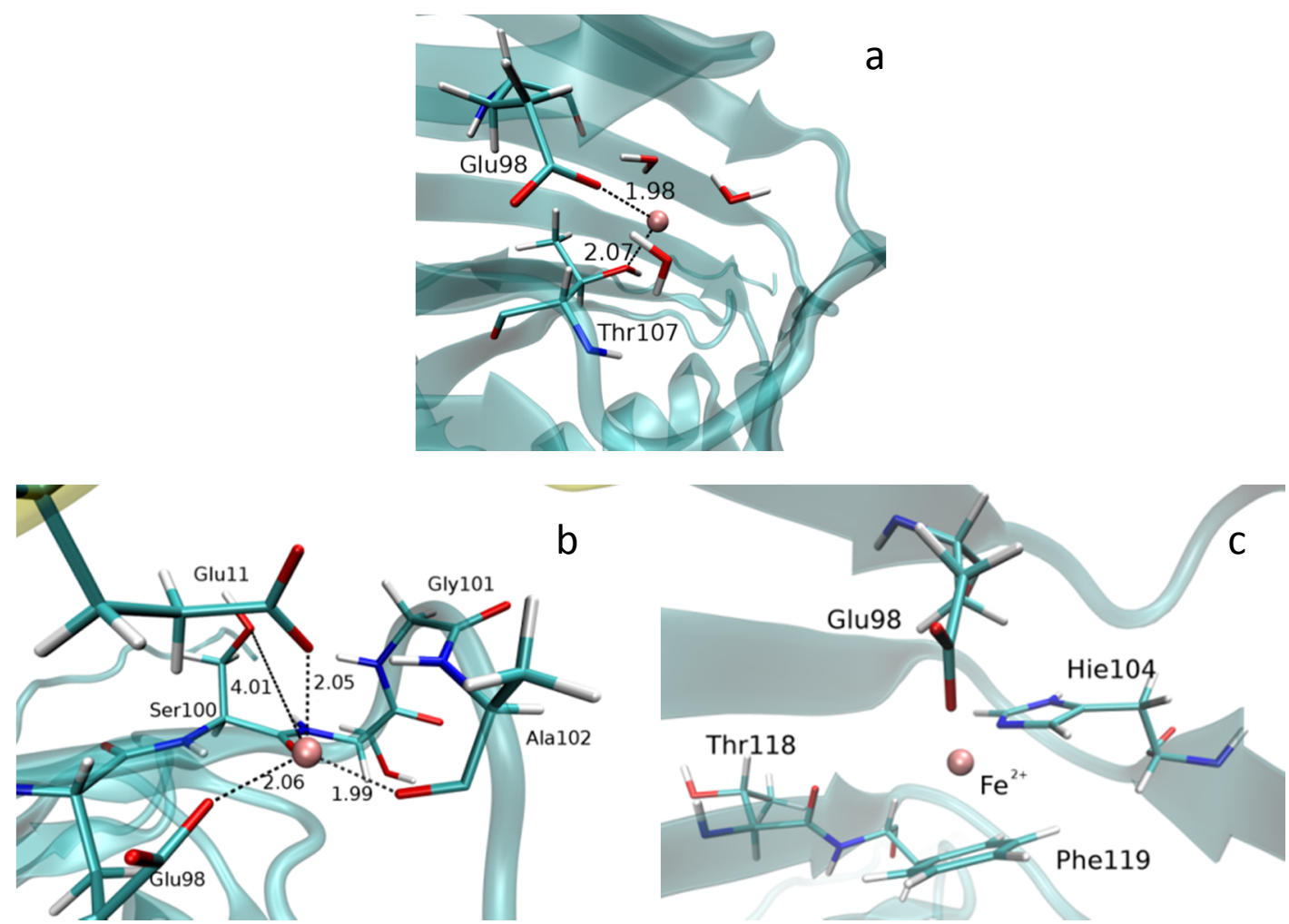

Figure 4. Positions of $\mathrm{Fe}^{2+}$ (pink ball) at the end of RAMD calculations: a) in the neighborhood of Thr107; b) close to Glu11 (from the neighbor subunit - the actually analyzed unit is given in transparent cyan, and neighbor subunit in yellow cartoon representation); c) next to Phe119. 
Table 9. The position of the metal ion, initially placed in the water trafficking tunnels within $2.5 \AA$ Af the Tyr70 residue side chain oxygen, determined after 16 ns of MD simulations (this region is part of both water trafficking tunnels, T1 and T2).

\begin{tabular}{|c|c|c|c|c|}
\hline \multirow[t]{2}{*}{ System to which Fe was added } & Unit A & Unit B & Unit C & Unit D \\
\hline & \multicolumn{4}{|c|}{ Position of the Fe dikation at the end of MD simulations } \\
\hline WT & CA & $\mathrm{D}$ & $A$ & D2 \\
\hline WT** & $\mathrm{A} 1$ & $\mathrm{D}$ & $A$ & $S$ \\
\hline WT* & $\mathrm{A} 1$ & $\mathrm{D}$ & $\mathrm{A} 1$ & $S$ \\
\hline $\mathrm{WT}+\mathrm{Fe}$ & D2 & D2 & $\mathrm{D}$ & D2 \\
\hline$W T+A C A C+F e$ & $\mathrm{D}$ & $\mathrm{D}$ & $D$ & $\mathrm{D}$ \\
\hline Tyr70Ala & $\mathrm{D}$ & CA & $\mathrm{D}$ & D2 \\
\hline Tyr70Ala * & D2 & $\mathrm{D}$ & $\mathrm{D}$ & $E$ \\
\hline Arg80Ala & $E$ & $\mathrm{D}$ & CA & D2 \\
\hline Glu98Gln & CA & D2 & D2 & D2 \\
\hline
\end{tabular}

$\mathrm{A}=\mathrm{Fe}^{2+}$ in the active site, coordinated with $\mathrm{E9} 8$ and $3 \mathrm{His}(\mathrm{s})=$ 'ideal' position

$\mathrm{A} 1=\mathrm{Fe}^{2+}$ in the active site, coordinated with $\mathrm{E9} 8$ and 1 or $2 \mathrm{His}$

$\mathrm{CA}=$ with respect to its initial position $\mathrm{Fe}^{2+}$ moved in the direction of the active site, and ended close to the 'ideal position' (within ca $5 \AA$ of it), but the coordination with E98 His(s) has not been established OR was established with only one of the $3 \mathrm{His}$ ligands

$\mathrm{D}=\mathrm{Fe}^{2+}$ in the 'ALTERNATIVE' BINDING site, coordinated with E98 AND E11 from neighbour subunit

$\mathrm{D} 1=\mathrm{Fe}^{2+}$ almost (close to) the 'ALTERNATIVE' BINDING site, coordinated with either E98 or E11 only

$\mathrm{D} 2=\mathrm{Fe}^{2+}$ moved from the initial to the 'ALTERNATIVE' BINDING site direction, but still have not accomodated in it (cordination with neither E11 or E98 was established)

$S=\mathrm{Fe}^{2+}$ at the protein surface (solvated), close to/coordinated to Glu 85

$E=\mathrm{Fe}^{2+}$ escaped from the protein into the bulk water

(Figure 4S(D)) where it became accessible to the bulky solvent. Alternatively, $\mathrm{Fe}^{2+}$ can be expelled into direction of Thr107 (the preferable path in the WT protein) as it is shown in Figure 4S(E) in supplementary material), where pink spheres represents motion of $\mathrm{Fe}^{2+}$ during RAMD. Remarkably, the preferred path for the $\mathrm{Fe}^{2+}$ ion in the WT enzyme was via a path that leads to Thr107 (Figure 4S(E)), where it rested, coordinated to the side chains of residues Glu78 and Thr107 while coordination to histidines was broken (see Figure 4). Notable, Thr107 has been reported to be crucial for $\mathrm{Fe}^{2+}$ binding. ${ }^{[6]}$ Thr107 and Arg80/Glu78 belong to two adjacent beta strands. The Glu78 and Thr107 side chains interact electrostatically and so has a crucial role in stabilization of these beta strands (see Figure $5 \mathrm{~S}$ in supplementary material).

In the Tyr70Ala and Arg80Ala variants the scenario depicted in Figure $4 \mathrm{~S}$ was additionally facilitated by the increased Glu98 mobility. Upon Tyr70 and Arg80 mutation, respectively, Glu98 was less constrained and it reoriented more easily than in the WT protein leading the $\mathrm{Fe}^{2+}$ ion in a distinct directions. Since during the simulations of the Glu98GIn variant the hydrogen bond between Arg80 and Gln98 was not established (Table 3) Gln98 was more flexible than the Glu in the WT enzyme however, it was still able to guide $\mathrm{Fe}^{2+}$ out of the metal binding site, wherein in about $40 \%$ of the cases metal ions were transferred to Glu11 of the neighbor subunit and in same amount of cases into direction of Phe119 (see Table 8 and Figure 4). Interestingly the $\mathrm{Fe}^{2+}$ coordination in the Glu98GIn mutant was not as tight as in the other variants.
In several cases the metal ion was expelled out of the protein. Expulsion of $\mathrm{Fe}^{2+}$ during simulations of the WT protein occurred through the water tunnel T2 (Table 8, see Figure S3 in previously published data ${ }^{[21]}$ for definition of tunnels). As a consequence of lack of the Arg80 side chain a large exit tunnel, composed of exits of both water tunnels, was formed in the Arg80Ala mutant. As the result the $\mathrm{Fe}^{2+}$ ion ended in the bulk water, out of the protein more frequently than it was the case during simulations of the other Dke1 variants.

Data strongly suggest that the exit path for the metal ion is generally via tunnel T2, so passing beside Glu98 and Glu11. This tunnel was broadened during simulations of the all investigated variants. The alternative pathway, tunnel T1, comprising Thr107, was only occasionally used for the $\mathrm{Fe}^{2+}$ expulsion.

\section{(v) Unrestricted Fe ${ }^{2+}$ Migration into the Protein}

In a complementary approach $\mathrm{Fe}^{2+}$ was placed into the water tunnels in vicinity (up to $2.5 \AA$ Á) of the Tyr70 side chain oxygen (which is part of both water trafficking tunnels) ${ }^{[5]}$ and subjected to unrestricted MD simulations over $16 \mathrm{~ns}$. In the wild type enzyme (apo form), $\mathrm{Fe}^{2+}$ was guided into/close to the 3-His 1-carboxylate metal binding site (defined as a $<2.5 \AA$ Á distance to all 3 histidine coordinated nitrogens) in 8 of 12 cases (see Table 9). In two cases $\mathrm{Fe}^{2+}$ got stuck on the protein surface, and in two cases it accommodated in the vicinity of Glu11. When either an $\mathrm{Fe}^{2+}$ ion or both, $\mathrm{Fe}^{2+}$ and substrate, were already bound in the binding site, the 
Table 10. The mean secondary structures determined for the variants after MD simulations, averaged over all subunits. Content of helices and sheets deviates up to $4 \%$ while content of turns within the proteins deviates up to $8 \%$

\begin{tabular}{cccc}
\hline Variant & Helix (\%) & Sheet (\%) & Turn (\%) \\
\hline WT & 7 & 48 & 21 \\
Tyr70Ala & 7 & 47 & 22 \\
Glu98GIn & 7 & 48 & 21 \\
Arg80Ala & 7 & 48 & 22 \\
\hline
\end{tabular}

other $\mathrm{Fe}^{2+}$ ion predominantly ended at the nonspecific binding site, bound to Glu11/Glu98 (see Table 9).

\section{Secondary Structure Analysis}

In order to quantify effect of the point mutation on the overall protein structure we analyzed their secondary structure before and after each MD simulation using the web server STRIDE. According to the results it seems that the introduced point mutations do not have induced protein refolding, i.e. no significant changes of the protein secondary structure during simulations were noticed, see Table 10.

\section{Discussion}

The present study clearly speaks in evidence of biphasic binding of the metal ion to Dke1, which was predicted by Leitgeb at al. ${ }^{[7]}$

According to the results of RAMD simulations, the $\mathrm{Fe}^{2+}$ ion when expelled from the binding site could be trapped at different locations within the enzyme. However, the largest number the RAMD simulations ended close to Glu11 (3 times or (19\%) in WT; 4 in Arg80Ala (25\%); 6 in Glu98GIn (38\%); 8 in Tyr70Ala (50\%), Table 8 and Figure $4 \mathrm{~b}$ ), which can be considered as an alternative, low affinity binding site. The number of $\mathrm{Fe}^{2+}$ trajectories ending out of the protein was the smallest in the case of the Dke1-WT (only two of sixteen), indicating that the Dke1- $\mathrm{Fe}^{2+}$ complex is more stable than the mutated complexes.

In accord with the RAMD simulations the binding free energy calculations (see Table 6) revealed the neighborhood of Glu11 (form the neighbor subunit) as the second most favorable binding site for the $\mathrm{Fe}^{2+}$ ion (after the active site).

Detailed analysis of the metal ion coordination and His104-Glu98-Arg80 interactions during the simulations revealed importance of Glu98 in the ion transport. Further on, Arg80 and Tyr70, through their interactions with Glu98, also influenced the $\mathrm{Fe}^{2+}$ transport.

Results of the long unconstrained MD simulations for the enzyme variants (Table 5) indicated that presence of the metal ion in the active site is the shortest in Arg80 mutant.
Hydrogen bond analyses revealed relocation of the GIn98 side chain of the Glu98GIn variant in direction of the neighbor beta strand during the MD simulations. Such behavior of Gln98 is in favor of the metal ion translocation out of the active site in direction of Glu11 from the neighbor subunit. During the simulations of Tyr70Ala variant guanidine end of Arg80 established strong interaction with Glu98. As a result an ideal trap for the metal ion has been formed between the carboxyl groups of Glu98 and Glu11 from the neighbor unit. Arg80 to Ala mutation caused relocation of Glu11 from neighbor subunit closer to His104, enabling formation of the Glu11(OE1/2) - His104(NE2H/CD2H) H-bond (Table 1), while in the WT protein His104 was strongly interacting with Glu98, which was at the same time often interacting with Arg80, during the simulations. Figure $4 \mathrm{~S}$ A-D indicate that Glu98, His104, Glu11 (from the neighbor subunit), and Arg80 interplay is crucial for the $\mathrm{Fe}^{2+}$ ion stabilization and transfer. Apparently $\mathrm{Fe}^{2+}$ affinity to bind to the glutamates carboxyl group is very high, since it spent the significant amount of simulations time coordinated either by Glu98 or Glu11, or both.

According to the computational results the metal ion could easier fluctuate between the active site and the alternative binding site next to Glu11 in the mutated (Tyr70Ala, Arg80Ala and Glu98GIn) enzymes than in the wild type. Yet, during the simulations of WT protein with $\mathrm{Fe}^{2+}$ initially placed in the water tunnel, the metal ion most often moved towards Glu11 (in $60 \%$ simulations and in direction of the active site in $25 \%$ simulations, see Table 9).

\section{CONCLUSIONS}

From the conducted computational analyses, mechanism of the $\mathrm{Fe}^{2+}$ trafficking in and out of the protein was elucidated. Interplay of Glu98, His104, Glu11 (from the neighbor subunit), and $\operatorname{Arg} 80$ residues is determined to be the most important for the $\mathrm{Fe}^{2+}$ transport. Also a place for the low affinity binding site is proposed, and it is in the vicinity of the Glu11 residue. Upon the point mutations of the hydrophilic residues Tyr70, Arg80 and Glu98 the metal ion is determined to be generally more flexible, so the role of the specified residues is shown to be important for metal stabilization in the active site.

Acknowledgment. The research was done in Physical Chemistry Department of Ruđer Bošković Institute in Zagreb, and Faculty of Medicine in Osijek. All MD simu lations were done using Isabella computing cluster (http://www.srce.unizg.hr/isabella/) and Croatian National Grid Infrastructure (www.cro-ngi.hr). 


\section{REFERENCES}

[1] K. J. Waldron, N. J. Robinson, Nat. Rev. Microbiol. 2009, 7, 25.

[2] G. Stranzl, Ph. D. Thesis, Institute of Chemistry, Karl Franzens University Graz, Graz, Austria, 2002.

[3] G. Straganz, L. Brecker, H.-J. Weber, W. Steiner, D. W. Ribbons, Biochem. Biophys. Res. Commun. 2002, 297, 232.

[4] G. Straganz, A. Glieder, L. Brecker, D. Ribbons, W. Steiner, Biochem. J. 2003, 369, 573.

[5] H. Brkić, D. Buongiorno, M. Ramek, G. Straganz, S. Tomić, J. Biol. Inorg. Chem. 2012, 17, 801.

[6] G. D. Straganz, A. R. Diebold, S. Egger, B. Nidetzky, E. I. Solomon, Biochemistry 2010, 49, 996.

[7] S. Leitgeb, G. Straganz, B. Nidetzky, Biochem. J. 2009, 418, 403.

[8] S. Velankar, C. Best, B. Beuth, C. H. Boutselakis, N. Cobley, A. W. Sousa Da Silva, et al., Nucleic Acids Res. 2010, 38, D308.

[9] D. Case, T. Darden, T. Cheatham III, C. Simmerling, J. Wang, R. Duke, et al., AMBER 12, 2012, San Francisco.

[10] Y. Duan, C. Wu, S. Chowdhury, M. C. Lee, G. Xiong, W. Zhang, et al., J. Comput. Chem. 2003, 24, 1999.
[11] J. Wang, R. M. Wolf, J. W. Caldwell, P. A. Kollman, D. A. Case, J. Comput. Chem. 2004, 25, 1157.

[12] H. Brkic, B. Kovacevic, S. Tomic, Mol. Biosyst. 2015, $11,898$.

[13] M. W. Mahoney, W. L. Jorgensen, J. Chem. Phys. 2000, 112, 8910.

[14] J.-P. Ryckaert, G. Ciccotti and H. J. Berendsen, J. Comput. Phys. 1977, 23, 327.

[15] B. R. Miller III, T. D. McGee Jr, J. M. Swails, N. Homeyer, H. Gohlke, A. E. Roitberg, J. Chem. Theory Comput. 2012, 8, 3314.

[16] M. L. Connolly, J. Appl. Crystallogr. 1983, 16, 548.

[17] S. Lüdemann, C. Lounnas, R. Wade, J. Mol. Biol. 2000, 303, 797.

[18] D. R. Roe, T. E. Cheatham III, J. Chem. Theory Comput. 2013, 9, 3084.

[19] M. Heinig and D. Frishman, Nucleic Acids Res. 2004, 32, W500.

[20] W. Humphrey, A. Dalke and K. Schulten, J. Mol. Graphics 1996, 14, 33.

[21] http://static-content.springer.com/esm/art:10.1007/ s00775-012-0898-8/MediaObjects/775_2012_898_ MOESM1_ESM.docx 
Supplementary material:

\begin{tabular}{|c|c|c|c|}
\hline & Duration [ns] & Variant & Description \\
\hline 1 & 16 & \multirow{11}{*}{ WT } & \multirow{2}{*}{$\mathrm{Fe}^{2+}$ ion initially placed into the active site } \\
\hline 2 & 30 & & \\
\hline 3 & 16 & & \multirow{4}{*}{$\mathrm{Fe}^{2+}$ placed at the entrance of the water trafficking tunnels } \\
\hline 4 & 6 & & \\
\hline 5 & 3 & & \\
\hline 6 & 5 & & \\
\hline 7 & $16 \times 0.25$ & & RAMD \\
\hline 8 & 6 & & APO-enzyme \\
\hline 9 & 6 & & Second $\mathrm{Fe}^{2+}$ placed at the water trafficking \\
\hline 10 & 8 & & Second $\mathrm{Fe}^{2+}$ placed at the water trafficking and ligand bound \\
\hline 11 & 30 & & With bonding parameters \\
\hline 12 & 16 & \multirow{8}{*}{ Tyr70Ala } & \multirow{2}{*}{$\mathrm{Fe}^{2+}$ ion initially placed into the active site } \\
\hline 13 & 30 & & \\
\hline 14 & 16 & & \multirow{3}{*}{$\mathrm{Fe}^{2+}$ placed at the entrance of the water trafficking tunnels } \\
\hline 15 & 5 & & \\
\hline 16 & 5 & & \\
\hline 17 & $16 \times 0.25$ & & RAMD \\
\hline 18 & 6 & & APO-enzyme \\
\hline 19 & 30 & & With bonding parameters \\
\hline 20 & 16 & \multirow{7}{*}{ Arg80Ala } & \multirow{2}{*}{$\mathrm{Fe}^{2+}$ ion initially placed into the active site } \\
\hline 21 & 30 & & \\
\hline 22 & 16 & & \multirow{2}{*}{$\mathrm{Fe}^{2+}$ placed at the entrance of the water trafficking tunnels } \\
\hline 23 & 5 & & \\
\hline 24 & $16 \times 0.25$ & & RAMD \\
\hline 25 & 6 & & APO-enzyme \\
\hline 26 & 30 & & With bonding parameters \\
\hline 27 & 16 & \multirow{7}{*}{ Glu98Gln } & \multirow{2}{*}{$\mathrm{Fe}^{2+}$ ion initially placed into the active site } \\
\hline 28 & 30 & & \\
\hline 29 & 16 & & \multirow{2}{*}{$\mathrm{Fe}^{2+}$ placed at the entrance of the water trafficking tunnels } \\
\hline 30 & 5 & & \\
\hline 31 & $16 \times 0.25$ & & RAMD \\
\hline 32 & 6 & & APO-enzyme \\
\hline 33 & 30 & & With bonding parameters \\
\hline
\end{tabular}

Table ST1. List of all simulations for each Dke1 variant, with respective duration of simulation 


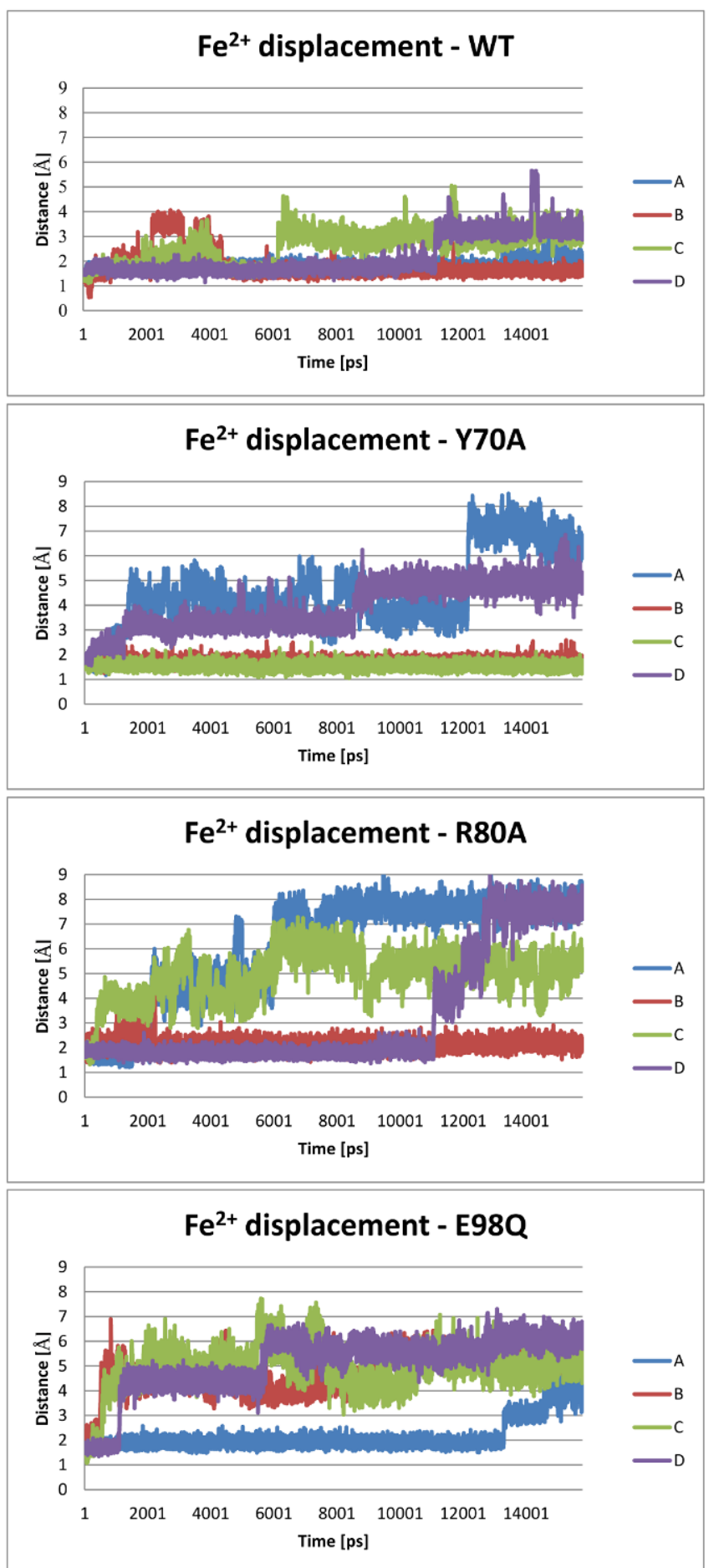

Fig. 1S Distances of metal ion from its initial position in four subunits during the first $16 \mathrm{~ns}$ of MD simulations at room temperature 


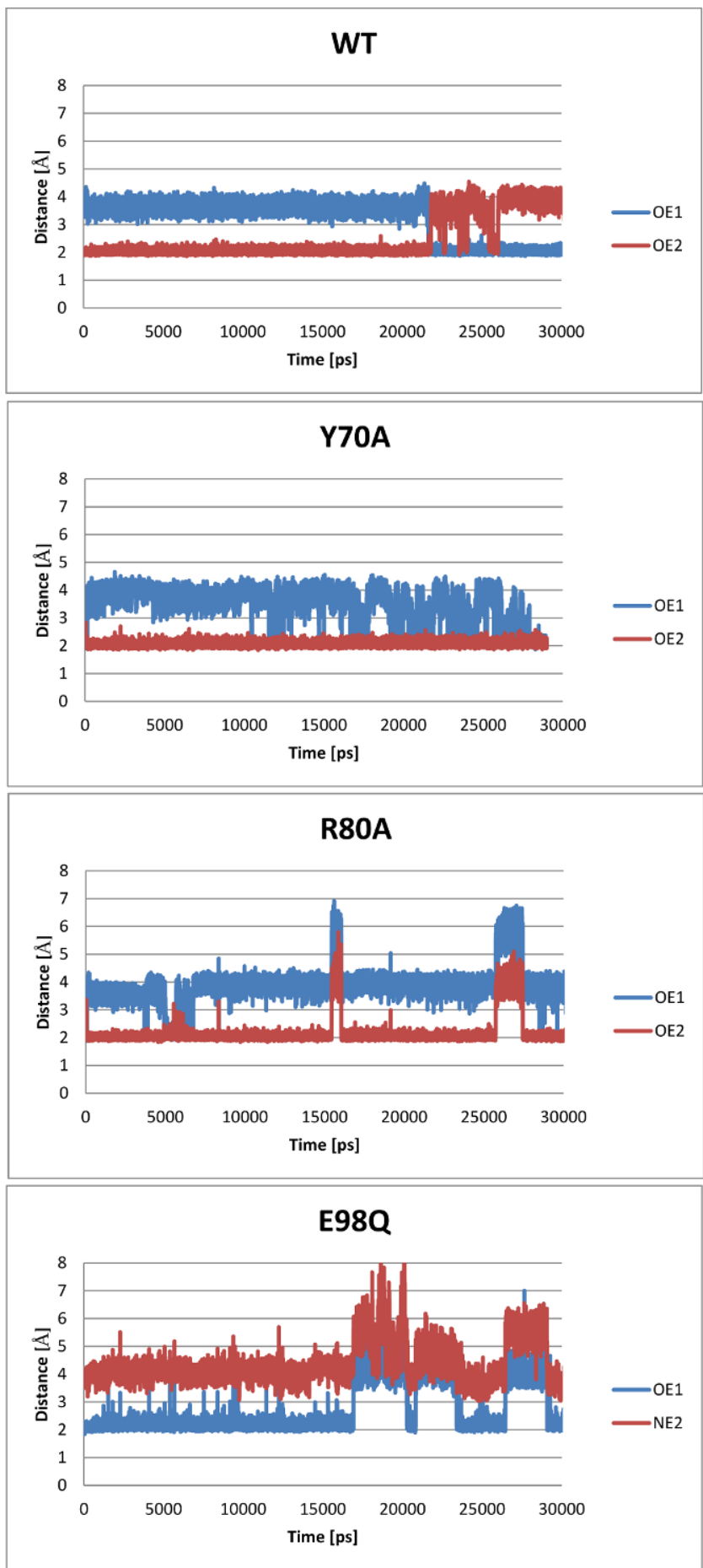

Fig. 2S The Glu/Gln98 $-\mathrm{Fe}^{2+}$ distances in one representative subunit (D) during first $30 \mathrm{~ns}$ of MD simulations at room temperature 

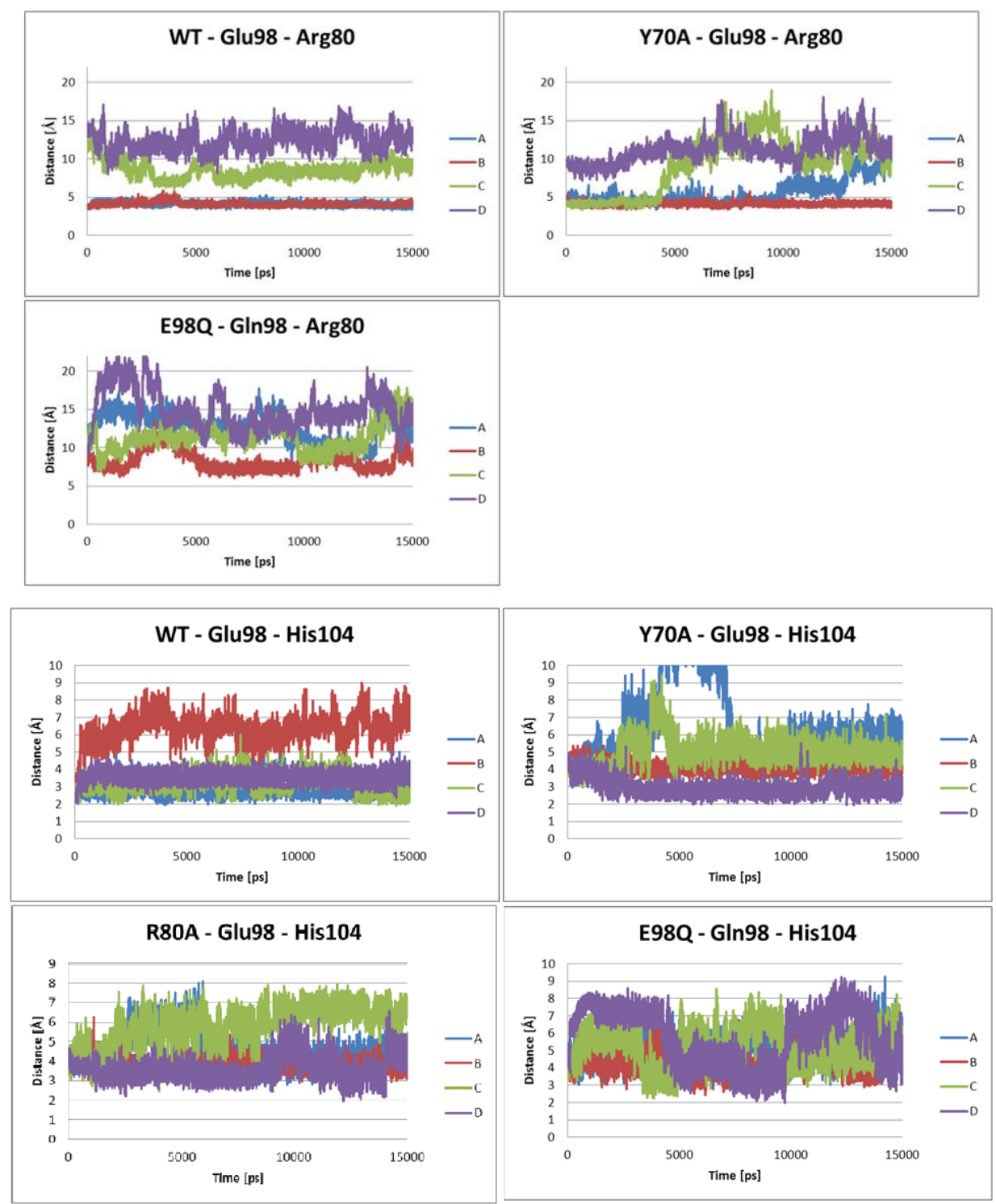

Fig. 3S Distances between Glu98 and Arg80 (and between His104 and Glu98) in four subunits during the first 15 ns of MD 


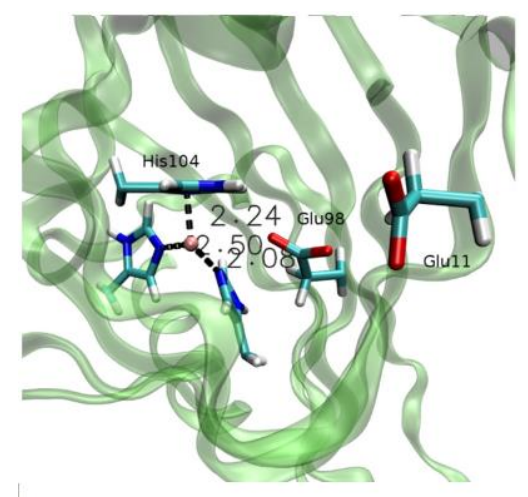

$\mathbf{A}$
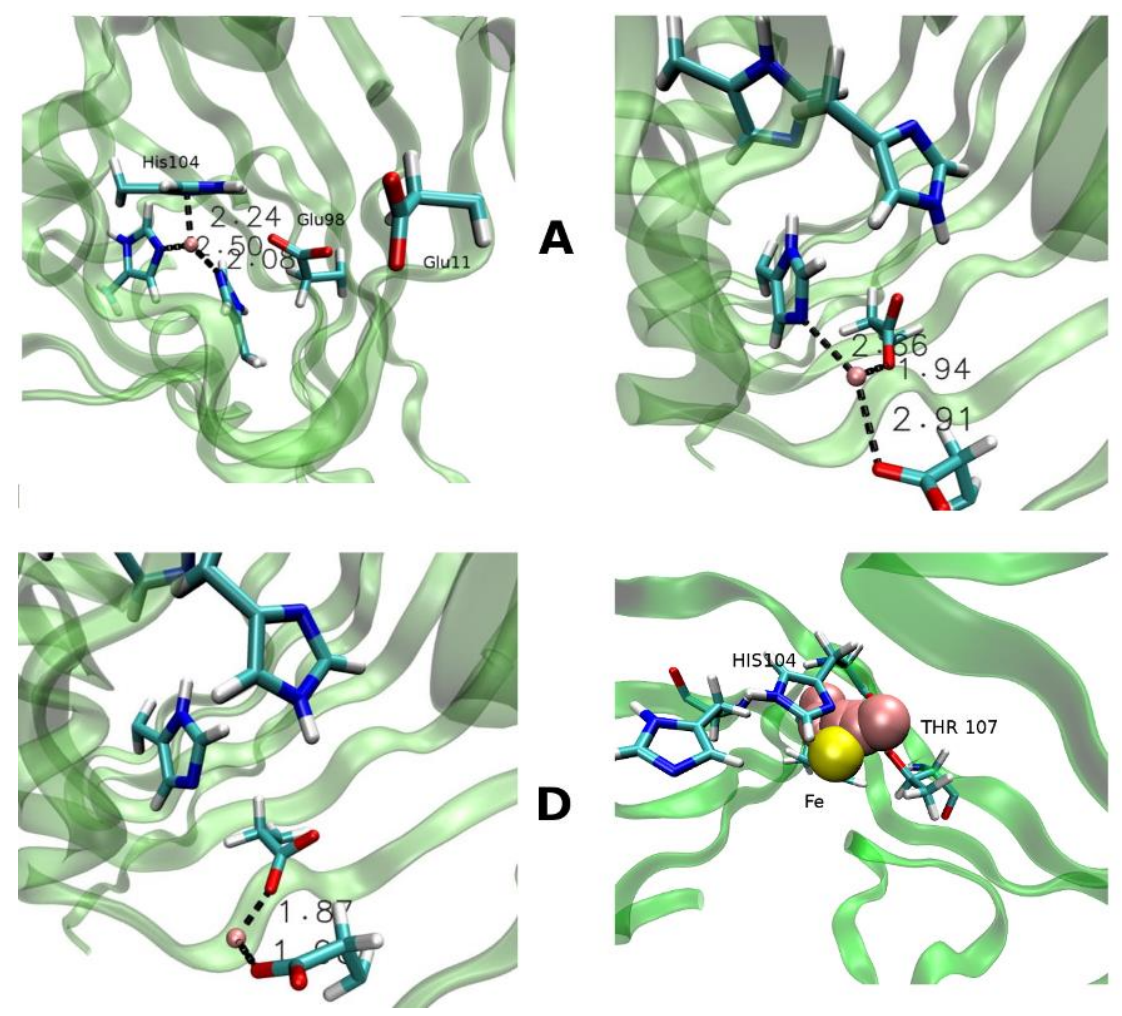

Fig. 4S Representation of a $\mathrm{Fe}^{2+}$ detachment trajectory. The $\beta$ strands shown in green transparent representations, the amino acid side chains in colored sticks, and $\mathrm{Fe}^{2+}$ as a pink ball (except in $\mathrm{E}$, where it is represented by yellow sphere). Black dashed lines represent bonds shorter $2.5 \AA$.
B

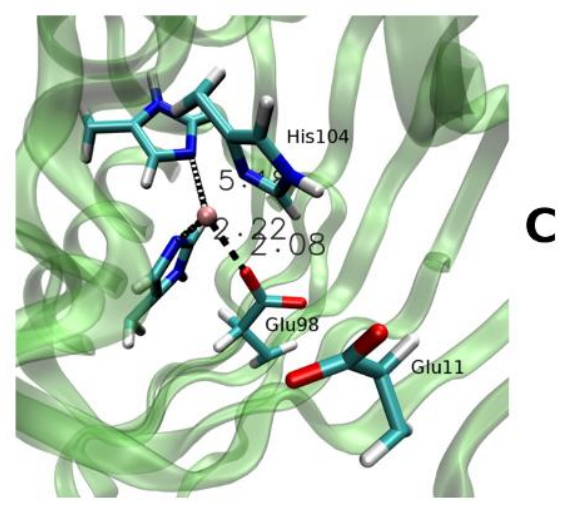

$\mathbf{E}$
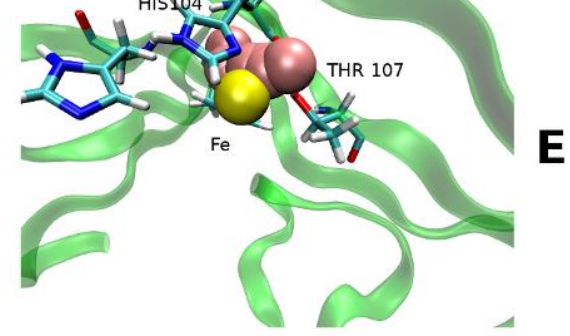

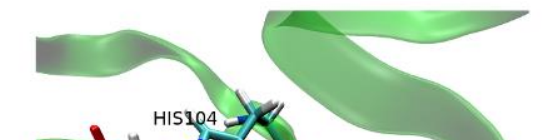

D 


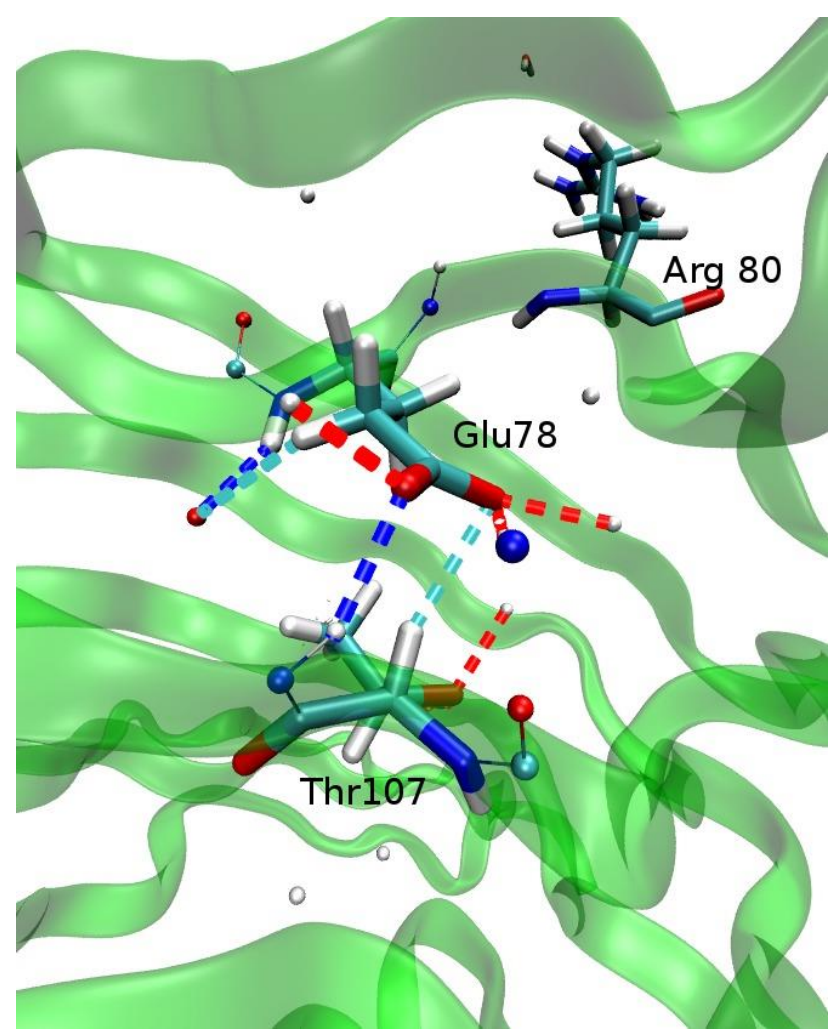

Fig. 5S Connections between Thr107 and Glu78 belonging to two adjacent beta strands. 


\section{Figure legends}

Fig. 1S Distances of metal ion from its initial position in four subunits during the first $16 \mathrm{~ns}$ of MD simulations at room temperature

Fig. 2S The Glu/Gln98 - $\mathrm{Fe}^{2+}$ distances in one representative subunit (D) during first $30 \mathrm{~ns}$ of MD simulations at room temperature

Fig. 3S Distances between Glu98 and Arg80 (and between His104 and Glu98) in four subunits during the first 15 ns of MD

Fig. 4S Representation of a $\mathrm{Fe}^{2+}$ detachment trajectory. The $\beta$ strands shown in green transparent representations, the amino acid side chains in colored sticks, and $\mathrm{Fe}^{2+}$ as a pink ball (except in $\mathrm{E}$, where it is represented by yellow sphere). Black dashed lines represent bonds shorter $2.5 \AA$.

Fig. 5S Connections between Thr107 and Glu78 belonging to two adjacent beta strands. 